\title{
Part I Introduction of the CCD Stereo Camera
}

\section{CCD Stereo Camera}

CE-1's optical sensor is a three-line-array CCD push-broom camera. The camera is loaded on a big area array CCD detector, reading the 11 st, $512 \mathrm{nd}$, and $1013 \mathrm{rd}$ rows perpendicular to the direction of flight. The data are regarded as the front, nadir and back image arrays, of which the pixel is 512 columns, and the view angle between adjacent arrays is $16.7^{\circ}$. Based on the predetermined in-orbit flight parameters, the camera's scanning speed is set to be $11.89 \mathrm{f} / \mathrm{s}$, to ensure that the satellite's three-line-array scanning can obtain consecutive image data on front, middle, and back angles (See in - Fig. 1.1). The main specifications of three-line-array CCD stereo camera are shown in $\bullet$ Tab. 1.1.

\section{Characteristics of Orbits and Attitudes}

The design parameters of CE-1 circumlunar orbits and attitudes are as follows (• Tab. 1.2):

(1) Orbital data in operation

CE-1's actual dynamic range of orbit altitude is from $195.53 \mathrm{~km}$ to $202.07 \mathrm{~km}$, with an average of $197.19 \mathrm{~km}$; the dynamic range of orbital eccentricity is from 0.00017 to 0.012293 , with an average of 0.006349 ; the dynamic range of orbital inclination is from $87.6^{\circ}$ to $90.0^{\circ}$, with an average of $88.20^{\circ}$.

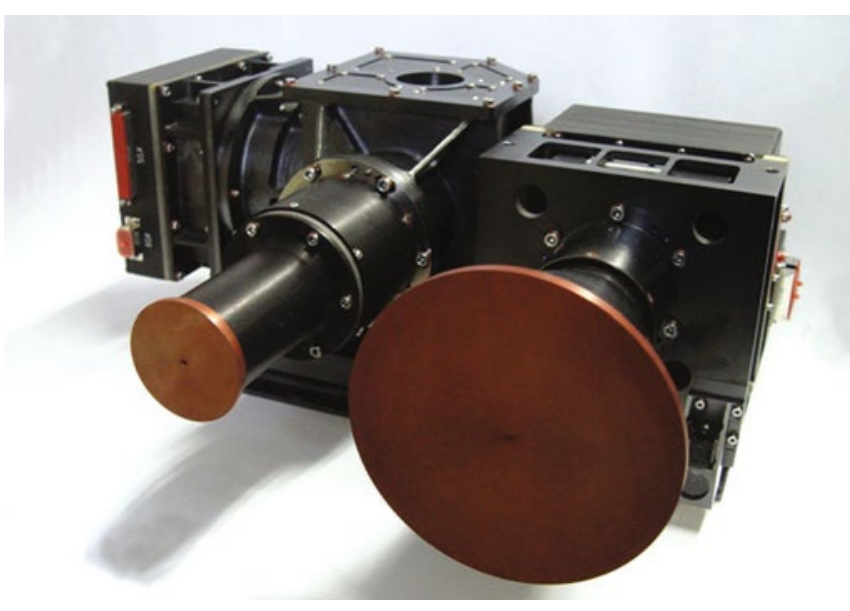

- CCD Stereo Camera
(2) Attitude data in operation

The attitude is relatively stable: more than $95 \%$ of attitude values are less than $0.03^{\circ}$ and standard deviation of the value of attitude angle to the Moon is less than $0.02^{\circ} ; 96 \%$ of the attitude change rate is less than $0.0016^{\circ} / \mathrm{s}$; stability of yaw angles and roll angles in orbit coordinates is better than $0.003^{\circ} / \mathrm{s}(3 \sigma)$; stability of pitch angles is better than $0.008^{\circ} / \mathrm{s}(3 \sigma)$

\section{Data Acquisition and Coverage}

Because of the adjustment of the orbit attitude, the maintaining of payloads, the global CCD image was finally fulfilled, after 4 covering cycles, in two operation periods, making the time phase of the image data inconsistent. During the first covering cycle, 228 tracks of data in areas of $70^{\circ} \mathrm{N}-70^{\circ} \mathrm{S}$ were acquired in the second period, 247 tracks from $70^{\circ} \mathrm{N}-70^{\circ} \mathrm{S}$ and 17 tracks from the polar regions were acquired; and in the third period (till January 27, 2008), 14 tracks from $70^{\circ} \mathrm{N}-70^{\circ} \mathrm{S}$ and 58 track from the polar regions were acquired. In the second operation period starting from May 1, 2008. 6 tracks from $70^{\circ} \mathrm{N}-70^{\circ} \mathrm{S}$ were acquired, fulfilling the data coverage in $70^{\circ} \mathrm{N}-70^{\circ} \mathrm{S}$. Data cover age of the polar regions were fulfilled on July 1

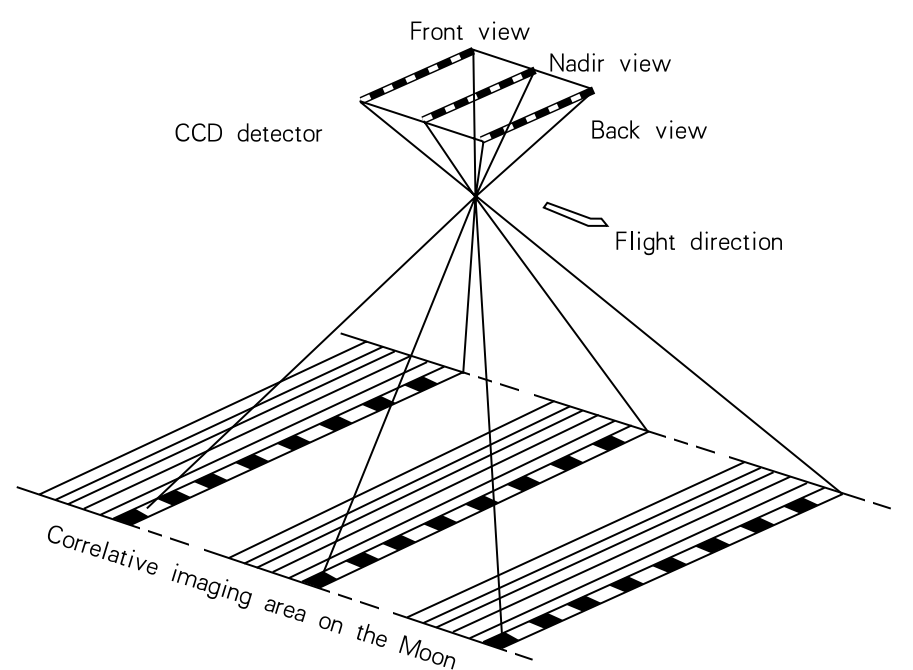

- Table 1.2 The design parameters of CE-1 circumlunar orbits and attitudes

\begin{tabular}{|l|l|}
\hline CE-1 parameter & Value \\
\hline Orbital altitude $(\mathrm{km})$ & $195.464 \pm 25$ \\
\hline Inclination & $90^{\circ} \pm 5^{\circ}$ \\
\hline Eccentricity & 0 \\
\hline Orbital period $(\mathrm{min})$ & 127.164 \\
\hline Attitude control precision (three dimensional) & $\pm 1^{\circ}(3 \sigma)$ \\
\hline Attitude change rate (three dimensional) & $0.01^{\circ} / \mathrm{s}(3 \sigma)$ \\
\hline
\end{tabular}

- Table 1.1 The main specifications of CCD stereo camera

\begin{tabular}{|l|l|l}
\hline Name & Index \\
\hline Frame frequency & $11.89 \mathrm{f} / \mathrm{s}$ \\
\hline Spectrum range & $0.5 \mu \mathrm{m} \sim 0.75 \mu \mathrm{m}$ \\
\hline Radiometric resolution & $8 \mathrm{bit}$ \\
\hline Focal length & $23.33 \mathrm{~mm}$ \\
\hline Pixel per linear array & 512 \\
\hline Size of pixel & $14 \mu \mathrm{m} \times 14 \mu \mathrm{m}$ \\
\hline Relative aperture & $\mathrm{F} / 5$ \\
\hline $\begin{array}{l}\text { Adjacent angle between linear } \\
\text { arrays }\end{array}$ & $16.7^{\circ}$ \\
\hline Time of exposure & $3.2 \mathrm{~ms}, 7 \mathrm{~ms}, 20 \mathrm{~ms}$ and $84 \mathrm{~ms}$ \\
\hline MTF & $\geq 0.2$ \\
\hline S/N ( $\rho=0.2 \theta=60)$ & $\geq 100$ \\
\hline Imaging width above 200 (km) & $\mathrm{L}=60 \mathrm{~km}$ \\
\hline Baseline to height ratio & $\geq 0.6$ \\
\hline $\begin{array}{l}\text { Pixel spatial resolution (subastral } \\
\text { point) }\end{array}$ & $120 \mathrm{~m}$ \\
\hline
\end{tabular}

- Fig. 1.1 CCD stereo camera imaging process 